\title{
Task Affect and Task Understanding in Engineering Problem Solving
}

\author{
Oenardi Lawanto, Angela Minichiello, Jacek Uziak, \& Andreas Febrian
}

\begin{abstract}
Within the self-regulated learning literature, motivation is considered to be an essential feature of students' self-regulatory processes. Additionally, task affect (i.e., personal objectives and task value) is thought to influence students' self-regulatory processes; insufficient task affect may lead to failures to selfregulate effectively. In a school setting, task affect is a form of motivation for completing the course tasks in order to attain course-level goals that are inherently valued. In this study, motivation is operationalized as students' personal objectives and task values, and self-regulation refers to students' understanding of tasks (also called task interpretation skill) involved in a course. This study investigates changes in students' task interpretation skill, personal objectives for learning, and task values, if any, while engaged in engineering problem-solving activities in a 2nd-year introductory thermodynamics course. This study also seeks to explore whether patterns exist between students' task understanding, personal objectives for learning, and task value while engaged in problem-solving activities throughout the course. The findings suggest that, as the semester progressed, both students' task value for the course and their focus on mastering the course material were continuously developed. Similarly, students' explicit and implicit task interpretation skills also improved as they engaged in problem-solving activities. However, it was found that implicit task interpretation skill was not developed as fully as explicit task interpretation when solving a complex problem; students seemed to understand $64-77 \%$ of the explicit and $39-49 \%$ of the implicit information presented to them.
\end{abstract}

Keywords: Engineering education; Personal objectives; Problem solving; Selfregulated learning; Task values; Task understanding

The idea for this study was generated by researchers' claims that students' motivation influences their self-regulatory processes (Butler \& Cartier, 2004b; Miller \& Brickman, 2004; Schunk, 1994). When confronted with a problem or task, students usually begin by generating thoughts, feeling, and actions focused on attaining the best solution to that problem (Butler \& Cartier, 2005; Pekrun, 2006). Ideally, those self-generated thoughts, feelings, and actions support effective forms of self-regulation.

Task interpretation (TI) is an important key component of self-regulation in action (Butler \& Cartier, 2004a, 2004b; Cartier \& Butler, 2004). Students' TI skill is an essential work habit in the pursuit of effective learning. Task interpretation skill includes students' ability to thoroughly interpret the demands 
of activities or tasks they are assigned. Research, however, suggests that students do not always approach activities as instructors intend (Butler, 1998; Cartier, 1997; Lawanto, et al., 2018; Wong, 1999). For example, significant gaps have been found between instructors' and students' TI skills in solving engineering problems (Lawanto et al., 2018).

Although Calkins, Willoughby, and Arnold (1982) reported that students' personal attributes may contribute to their academic achievement, it is not yet clear how students' personal attributes contribute to the quality of their task interpretation TI during engineering problem solving. Task affect (TA), such as students' personal objectives and task values in a course, interact with their TI and shapes the quality of their problem-solving activities. Thus, TA is part of students' metacognitive knowledge about tasks (Flavell, 1979). This study focused on the key roles of TA and TI as part of iterative problem-solving processes.

\section{Literature Review}

\section{Task Understanding as the Heart of Self-Regulated Learning}

Self-regulated learning (SRL) posits that students' metacognitive, behavioral, and motivational engagement in their cognitive processes play an essential role in successful and enduring learning (Andrade \& Valtcheva, 2009; Boekaerts, 1997; Coutinho, 2007; Lawanto, Butler, Cartier, Santoso, \& Goodridge, 2013; Otero, Campanario, \& Hopkins, 1992; Wolters, 1998; Zimmerman, 1989). According to Zimmerman (1989), self-regulated learners are "metacognitively, ... motivationally, and behaviorally active participants in their own learning process" (Zimmerman, 1989, p. 329); therefore, selfregulated learners are skilled in goal setting, self-monitoring, self-instruction, and self-reinforcement (Schraw, Crippen, \& Hartley, 2006). In this study, SRL is defined as students' repository of knowledge and skills for planning, implementing, monitoring, evaluating, and continually improving the learning process (Butler \& Cartier, 2005; Butler \& Winne, 1995). Students with strong SRL skills are considered more knowledgeable and responsible for their cognition (Pintrich, 2002) and expected to accomplish cognitive actions more successfully (Paris, 1986). Students with weak SRL skills may benefit from instructional practices that are purposely designed to improve students' metacognition, interest, and motivation for learning (Coutinho, 2008; Marchis, 2011; Samuelsson, 2008).

Although SRL is directly tied to metacognition as a cognitive control process, it also involves the actions that students take based on their metacognitive knowledge. For example, Dinsmore, Alexander, and Loughlin (2008) suggest that there is a "clear cognitive orientation for metacognition, while self-regulation is as much concerned with human action than the thinking that engendered it" (p. 405). Researchers maintain that to understand the 
interplay between self-regulation and metacognition is to understand "the correspondence between metacognition and action. How do thoughts and feelings of students guide their thinking, effort, and behavior?" (Paris \& Winograd, 1990, p. 21).

The dynamic and iterative interplay between metacognitive and cognitive activities is described by Butler and Cartier (Brydges \& Butler, 2012; Butler \& Cartier, 2005; Butler \& Winne, 1995). Their model involves layers of context, individual attributes, mediating variables, TI and personal objectives, selfregulating processes, and cognitive strategies. During engineering problem solving, multiple contexts may include learning expectations in engineering as a field of study, the nature of problem-solving tasks, and the expectations of the instructor.

Recognizing the ways in which multiple interwoven contexts shape and constrain the quality of student engagement in learning is essential for SRL understanding. The individual attributes that students bring to the learning context are, among others, strengths, challenges, interests, and preferences. Over time, students accumulate a learning history that shapes the development of knowledge, skills, self-perceptions, attitudes toward school, and concepts about academic work (Butler \& Cartier, 2004a; Cartier \& Butler, 2004; Schoenfeld, 1988). The mediating variables include students' knowledge, perceptions about competence and control over learning, and perceptions about activities and tasks. Variables also include emotions experienced before, during, and after completing a task. These mediating variables impact the way students interpret any tasks they encounter.

Task interpretation refers to students' construction of an internal representation of the externally assigned task (Butler \& Cartier, 2004b; Hadwin, Oshige, Miller, \& Wild, 2009) and is the heart of SRL, insofar as it shapes key dynamic and recursive self-regulating processes. It is anticipated that TI and TA influence how students activate self-regulating and cognitive actions during problem-solving activities. This research focuses on explicit and implicit information about tasks, two layers of information suggested in Hadwin, Oshige, Miller, and Wild's (2009) model of task understanding. Explicit features of a task include information that is overtly presented in problem descriptions found in the course textbook and class discussions. Implicit features of a task include any information beyond the problem description, such as relevant concepts and useful resources needed to solve problems.

Through effective TI and SRL, problem solving can be conceptualized as a series of steps that may include self-perception about the value of the class or assigned problems associated with the class, reading the problem statements, self-asking critical questions associated with explicit and implicit features of the task, and understanding of the problem to be solved. In previous studies, it has been found that students generally have an incomplete understanding of the assigned tasks and often struggle to establish a connection between what they 
have learned and tasks they are required to complete (Lawanto et al., 2018; Lawanto, Butler, Cartier, Santoso, Goodridge, Lawanto, \& Clark, 2013).

\section{Task Affect in Problem Solving}

Task affect is broadly defined as students' emotion toward an engaged task, which may manifest as their personal objectives (PO) and task value (TV) during the TI process. Students' PO relate to the reasons why individuals engage in given tasks. In this study, PO refers to the beliefs that induce one to approach, engage in, and respond to tasks in different ways (Ames, 1992). Research on goal orientation (GO) has shown that there are two general GO: mastery and performance. Mastery refers to the one's focus on learning and mastering the material; performance refers to one's demonstration of abilities and achievement to others (Wolters, Yu, \& Pintrich, 1996). Mattern (2005) found that there is a difference in terms of students' achievement between mastery-learning and performance-learning groups and that students who held mastery-learning GO obtained higher achievement outcomes compared with those who held performance-learning GO.

Task value refers to students' perceptions of the extent to which the task is important (attainment value), interesting (intrinsic value), and useful (utility value; Eccles, 1983; Pintrich, Smith, Garcia, \& McKeachie, 1991). Task attainment value refers to students' perceived importance of a task with respect to their identity or competence in a particular domain (Wigfield, 1994). Using a cognitive perspective, Markus and Wurf (1987) related this aspect to individual self-schemata. Understanding students' prior knowledge will be helpful to posit the design task in their existing schemata. Interest refers to subjective interest in the activity. Usefulness is determined by the extent to which students relate the task to their short- and long-term goals. Previous studies have reported that TV is often positively related to self-efficacy, and both TV and self-efficacy have been documented as effective predictors of academic outcomes (Bong, 2004; Multon, Brown, \& Lent, 1991).

\section{Research Design and Method}

\section{Purpose and Research Questions}

The purpose of this study is to investigate changes in students' task interpretation (TI) skill and task affect (TA), if any, while engaged in problemsolving tasks during an introductory engineering thermodynamics course. This study also seeks to understand whether improvements in students' task value (TV) and emergent use of mastery learning goal orientation (GO) are reflected in changes in students' task interpretation skill during the course. Findings from this research are expected not only to improve the effectiveness of teaching engineering problem solving but also to develop more positive attitudes toward problem solving among engineering students. 
Two research questions were developed to guide this research:

1. How are changes in students' $T V$, if any, reflected in changes of students' PO throughout the course?

2. How do student's TI skills change while engaged in problem-solving tasks throughout the course?

\section{Context of the Study}

Engineering Thermodynamics, a foundational sophomore-level course that is required for mechanical engineering and related majors, was selected as the context of this study. The goal of this course is to examine the relationships between different energy forms (i.e., heat and work) and to develop students' ability to analyze energy transformation processes and cycles. Within the course, weekly problem sets were assigned in the manner proposed by Kearsley and Klein (2016). Problem solving assignments were posted electronically to the course learning management system (LMS) and students were given one week to solve and turn in their handwritten solutions by scanning and uploading them to the LMS. Once students submitted their prepared solutions, the instructor posted detailed solution procedures for the problem sets. Students were expected to review their work against the posted solutions, correct their work with a different color marker, and re-submit their corrected work to the LMS. Students were also asked to reflect on their work and add notes or comments to their papers highlighting ideas or concepts they learned during the correction process. Student assignments were graded using a rubric that considered the effort exhibited during the first submission and the manner the work was corrected and annotated for the second submission.

Initially, 112 students volunteered to participate in the study; however, only sixty-eight (68) students (10 female and 58 male) completed all the data collection tasks during in the study. Participation was voluntary and participants were reminded that they could withdraw at any time. The participants were informed of the purpose of the study during class by a researcher who was not the course instructor. The researchers encouraged students to participate by offering compensation for their participation in the form of a maximum of eight extra credit points. Students who chose not to participate were given the opportunity to earn equivalent extra credit points by working on other assignments requiring a similar level of effort. Students who participated were required to sign a consent form as part of the processes approved by the Institutional Review Board.

\section{Instruments}

The participants' PO, TV, and TI were collected using an open-ended survey, a modified version of the Motivated Strategies for Learning Questionnaire (MSLQ), and Task Analyzer Questionnaires (TAQ), respectively. 
The open-ended survey asked students to provide an explanation of three personal objectives clarifying what they would like to gain from taking this class.

The MSLQ is a self-reporting instrument developed by Pintrich, Smith, Garcia, and McKeachie (1991) to assess college students' motivational orientations and their use of different learning strategies. The Cronbach's alpha coefficient of this TV scale was .90. For this study, MSLQ's modifications were made in order to restate the questions in the context of this study. For example, the statement "It is important for me to learn the course material in this class" in the MSLQ and was modified to read "It is important for me to learn the skills/content taught in MAE2300 Thermodynamics." The wording of the questionnaire became the focus of instrument modification because students typically distinguish between their capabilities for dealing with two or more characteristically different topics or problems within the same measurement parameter (Bong, 1999). Face validity was conducted prior the data collection by involving five students and two content experts, and found these modifications did not introduce any threat to the instrument validity. When filling-out the modified TV-MSLQ, students rated themselves on a 7-point Likert scale, from "not at all true of me" (a score of 1) to "very true of me" (a score of 7). The modified TV-MSQL is presented in the Appendix.

In order to collect students' TI of the problems they were required to solve during the semester, the researchers purposely selected three problems (Tasks 1 , 2, and 3) from Çengel and Boles (2015) that represented core issues in weeks 7, 12 , and 15 of the course. Each problem was related to one unique course topic including (Task 1) Closed System Energy Analysis (First Law), (Task 2) Open System Entropy Balance (Second Law), and (Task 3) Ideal Cycle Analysis. The level of difficulty of the problems assigned during this study reflected the same level of difficulty as the problems that were discussed in class, assigned for preparation out of class, and assessed during exams. Due to the cumulative nature of content within the course, the first problem could be considered as the least complex and the last problem as the most complex if compared against each other. The students' TI were collected through the TAQs, and unique TAQs were developed for each assigned problem. Each TAQ consisted of eight open-ended questions and included items related to both explicit and implicit aspects of TI. The TAQ for Task 1 is presented in the appendix as an example.

\section{Data Collection and Analysis}

Data were collected from participants who were enrolled in Engineering Thermodynamics course throughout the spring 2017 semester. Students' TV and PO were assessed twice, at the first and last weeks of the semester using the modified TV-MSLQ and open-ended survey, respectively. These recorded PO were coded and categorize into mastery or performance goal orientations (GO) by two coders and $96 \%$ of inter-rater reliability score between the two coders 
was achieved. Frequency count was then performed for each category to identify students' GO.

Two raters assessed students' TI of each problem: the course instructor and another engineering faculty content expert. The instructor provided initial TAQ responses, which were evaluated by the expert. After discussions between the instructor and content expert, revisions were made to the instructor's responses and were used to score students' responses. We believed the revised instructor's TAQ responses had minimal bias.

TAQ scores ranged between from 0 to 2; a TI score of 0 was assigned to a blank or incorrect answer and a score of 2 was given to a correct answer. The score applied to an incomplete answer was mutually agreed on by the raters. The agreement between raters also served to minimize bias and improve score reliability. When students were only able to describe less than half of the possible correct responses, they were given a 1 for their TI score. Together, the two raters achieved an inter-rater reliability score of $97 \%$ agreement. This TI score represented students' TI skill on a particular problem-solving task. At this point, all the qualitative data were converted into quantitative data. Examples of students' complete and incomplete answers are provided in the Appendix.

To investigate any potential changes of students' TV from the beginning to the end of the semester, their TV mean and standard deviation scores were calculated and compared. Furthermore, the frequency (in percent) of students' mastery and performance GO of the course at the beginning and end of the semester were compared. The sign test and paired-sample $t$-test were used to assess whether the changes of TV and GO were statistically significant. The sign test was used due to the nature of the paired-TV data which were in an ordinal scale and did not have a similar shape.

The answer to the second research question was achieved by comparing means of students' TAQ responses among the three problem-solving tasks and task affects (TA) (i.e., TV and PO). Next, two-tailed paired-sample $t$-tests were conducted. A cutoff value of .05 for Type 1 error was used to determine whether the results of the TAQ before and after are significant. Descriptive statistics were also performed to determine changes, if any, in students' TA and their TI skill through the semester.

\section{Results}

\section{Addressing Research Question 1: How are changes in students' TV, if any, reflected in changes of students' PO throughout the course?}

Descriptive statistics results show a trending pattern of continuous increase of students' development of TV scores (i.e., overall, utilities, importance, interesting) for the course (see Table 1) and all except the importance score were statistically significant (see Table 2). Similarly, there was a trend of a growing focus on mastery GO towards the end of the semester which suggests that as the 
semester progressed, both students' task value for the course and their focus on mastering the course material were continuously developed (see Table 3). The $t$ test confirmed these transitions were statistically significant for both mastery $(t$ $=-4.146, p=<.001)$ and performance $(t=5.889, p=<.001) \mathrm{GO}$. As the semester progressed, students perceived the material learned was more interesting (from a mean value of 5.220 to 5.676) and useful (from a mean value of 6.008 to 6.153). This finding suggests that if students value course content, they might consequently become more focused on mastering the course material (i.e., mastery GO) rather than simply getting good grades and/or passing the course (i.e., performance GO).

Table 1

Students' Task Value Mean (SD) Score at the Beginning and End of the Semester

\begin{tabular}{cccccccc}
\hline \multicolumn{3}{c}{ At the beginning of the semester } & \multicolumn{3}{c}{ At the end of the semester } \\
\hline $\begin{array}{ccccccc}\text { Overall } \\
\mathrm{TV}\end{array}$ & $\begin{array}{c}\text { Utility } \\
\mathrm{TV}\end{array}$ & $\begin{array}{c}\text { Importance } \\
\mathrm{TV}\end{array}$ & $\begin{array}{c}\text { Interest } \\
\mathrm{TV}\end{array}$ & $\begin{array}{c}\text { Overall } \\
\mathrm{TV}\end{array}$ & $\begin{array}{c}\text { Utility } \\
\mathrm{TV}\end{array}$ & $\begin{array}{c}\text { Importance } \\
\mathrm{TV}\end{array}$ & $\begin{array}{c}\text { Interest } \\
\mathrm{TV}\end{array}$ \\
\hline $\begin{array}{c}5.757 \\
(0.815)\end{array}$ & $\begin{array}{c}6.008 \\
(0.999)\end{array}$ & $\begin{array}{c}6.045 \\
(1.005)\end{array}$ & $\begin{array}{c}5.220 \\
(1.193)\end{array}$ & $\begin{array}{c}5.957 \\
(0.972)\end{array}$ & $\begin{array}{c}6.153 \\
(1.045)\end{array}$ & $\begin{array}{c}6.042 \\
(1.140)\end{array}$ & $\begin{array}{c}5.676 \\
(1.275)\end{array}$ \\
\hline
\end{tabular}

Table 2

Significant Changes of Students' Task Value

At the beginning vs. end of the semester

\begin{tabular}{lcc} 
& $z$ & $p$ \\
\cline { 2 - 3 } Task value & & $<.01$ \\
Overall & -2.785 & $<.01$ \\
Utility & -2.729 & $>.05$ \\
Importance & -0.912 & $<.001$ \\
Interest & -4.556 & \\
\hline
\end{tabular}


Table 3

Students' Learning versus Performance Frequency (Percentage) Count at the Beginning and End of the Semester

\begin{tabular}{ccccc}
\hline \multicolumn{2}{c}{ At the beginning of the semester } & & \multicolumn{2}{c}{ At the end of the semester } \\
\cline { 1 - 2 } \cline { 4 - 5 } Mastery GO & Performance GO & & Mastery GO & Performance GO \\
\hline $71 \%$ & $29 \%$ & & $90 \%$ & $10 \%$ \\
\hline
\end{tabular}

\section{Addressing Research Question 2: How do student's TI skills change while} engaged in problem-solving tasks throughout the course?

It was interesting to find that, despite engaging in increasingly complex problem-solving activities, students demonstrated increased TI scores (overall, explicit, and implicit) during the course (see Table 4). The overall TI score increased from 1.028 (i.e., 51\%) to $1.159(58 \%)$. Similarly, students' explicit TI scores increased from 1.283 (i.e., 64\%) to 1.546 (i.e., 77\%); students' implicit TI scores increased from 0.774 (39\%) to 0.985 (i.e., 49\%). A decreased implicit TI in Problem \#3 might be caused by the complexity of the particular problem (further discussion for this can be found in Lawanto, Minichiello, Uziak, and Febrian (2018).

To investigate whether there was TI skill change during the course, six sets of paired $t$-tests were conducted (see Table 5). The first test was conducted to evaluate the mean differences between TI scores on early semester (TAQ \#1) and mid semester (TAQ \#2), and between TI scores on mid semester (TAQ\#2) and end semester (TAQ\#3). The results suggest that there was a significant increase of students' overall TI score between solving problem at the beginning (TAQ \#1) and mid semester (TAQ \#2), $t(68)=-0.348, p<.001$. This significant increase of overall TI score may be caused by a significant increase of students Implicit Task Interpretation score, $t(68)=-4.901, p<.001$, whereas the increase of students' explicit task interpretation score was noted but was not significant, $t(68)=-0.888, p>.05$. There was a significant increase of students' explicit interpretation score between solving problem at the mid (i.e., TAQ \#2) and end semester (i.e., TAQ \#3), $t(68)=-4.455, p<.001$. There was a significant decrease of students' implicit score during solving problem at the end of the semester compared to mid semester, $t(68)=4.639, p<, 001$. This may be due to the increased complexity of the problem that students were required to engage at the end of the semester (i.e., Task 3), see a study reported by Lawanto et al. (2018). These significant increase and decrease of students explicit and implicit task interpretation scores appeared to make change in students' overall TI score of solving problem between mid and end semester, $t(68)=0.000, p>.05$. 
Table 4

Students' Task Interpretation Scores (Mean and Percentage) over the Three Assigned Problems

\begin{tabular}{lccc}
\hline & $\begin{array}{c}\text { Problem 1 } \\
\text { early semester }\end{array}$ & $\begin{array}{c}\text { Problem 2 } \\
\text { mid semester }\end{array}$ & $\begin{array}{c}\text { Problem 3 } \\
\text { end semester }\end{array}$ \\
\hline Overall TI score & $1.028(51 \%)$ & $1.159(58 \%)$ & $1.159(58 \%)$ \\
Explicit TI score & $1.283(58 \%)$ & $1.333(67 \%)$ & $1.546(77 \%)$ \\
Implicit TI score & $0.774(39 \%)$ & $0.985(49 \%)$ & $0.772(39 \%)$ \\
\hline
\end{tabular}

Table 5

Significant Changes of Students' Task Interpretation Scores over the Three Assigned Problems

Problem 1 (early semester)

vs.

Problem 2 (mid semester)
Problem 2 (mid semester)

vs.

Problem 3 (end semester)

\begin{tabular}{|c|c|c|c|c|}
\hline & $t$ & $P$ & $t$ & $p$ \\
\hline Overall TI score & -0.348 & $<.001$ & 0.000 & $>.05$ \\
\hline Explicit TI score & -0.888 & $>.05$ & -4.455 & $<.001$ \\
\hline Implicit TI score & -4.901 & $<.001$ & 4.639 & $<.001$ \\
\hline
\end{tabular}

\section{Conclusions and Discussion}

Most engineering instructors may expect that students become more appreciative to their teaching and interested in mastering the course content as the academic semester progresses. That expectation was fulfilled in the Engineering Thermodynamics class in this research study. Students' task value about the course at the end of the semester was higher than when they just began taking the class. The students seemed to be able to see the usefulness of the course content and perceived that the course had become more interesting as they continued participating in the class. The increase in students' perceptions of the usefulness and attractiveness of the course were also reflected by the shift of their personal objectives. As the semester progressed, students seemed to be more focused on mastering the course content than merely getting good grades or passing the course.

Moreover, it was also found that as the semester progressed, and the problems became more complex, students' task interpretation scores improved. Students' explicit and implicit task interpretation scores continued to increase except when students were engaged in solving a complex problem (i.e., Task 3). Further analyses of the $t$-tests revealed significant differences between the 
students' ability to identify the explicit and implicit information associated with the assigned task (see Tables 4 and 5). Student scores indicate a higher ability to identify the explicit understanding of problem than the implicit one. This suggests that the students seemed to experience more challenges to identify information beyond the problem description, such as identifying the purpose of the problem assigned and connections to learning concepts. Although implicit information often seems obvious to the instructors, students may face difficulty in making the connections between information that is presented in problem description and information that the students need to extrapolate beyond the problem description.

Despite higher explicit task interpretation scores, instructors may not expect students to be able to grasp all of the explicit information given by the problem description. The findings show that students seem to be able to grasp $64-77 \%$ of explicit and 39-49\% of implicit information presented to them while engaged in problem-solving activities. This finding aligns with the novice-expert research findings that suggest experts spend more time on understanding the task and engaging in monitoring and evaluation, in the attempt to develop more complete representation of the problems before finding the appropriate strategies to solve them (Abelson, 1981; Glaser, 1992; Herbig \& Glöckner, 2009; Hoffman, 1998; Lesgold et al., 1988).

Although it is inconclusive, the analyses revealed a trending pattern in that students' TI scores improved as their appreciation of course topics and focus on the mastery of the course content increased. The results indicate that the change of students' affect (represented by students' TV and PO) seemed to be reflected on the change of their TI skill. Although it is statistically inappropriate to correlate these outcomes since the interplay between students' perception of the course (i.e., students' TA) and their TI of specific course-related problems is still unclear. These results suggest that engineering students' TA may be related to their explicit TI skill. Further research is suggested in this area.

Although continuous improvement of students' explicit TI skills was apparent during problem-solving activities, improvement in students' implicit TI skill was noted only during the beginning and mid of the semester (i.e., Tasks 1 and 2). Students seemed to have trouble identifying implicit information in a more advanced problem that required them to gather the cumulative content knowledge learned within the course. Further investigation is needed to better understand how students' PO and TV for solving particular problems relate to their explicit and implicit TI skill.

\section{Implications}

The results of this study, which point to the malleability of student TA and $\mathrm{TI}$ in engineering problem solving, have important implications for teaching practice. First, results suggest that both the value that students place on engineering problem-solving tasks and their ability to interpret problem-solving 
tasks of increasing complexity can be substantially improved during a semester. Moreover, results may further suggest that the ways in which graded problem solving assignments are administered may positively affect students' TA and explicit TI. For example, purposeful attempts by instructors to engage students in reflection, correction, and self-evaluation of their problem-solving skills and performance on each assignment may be an effective approach for improving engineering students' TA and TI.

Second, the results showcase the varying degrees to which instruction might affect explicit and implicit TI of engineering students. Results of this study show that it is important for instructors to realize the multi-faceted nature of TI so that they can adequately scaffold and support both explicit and implicit TI. Results further suggest that instructors should devote more time to promoting development of implicit TI during engineering problem solving with increasingly complex problems.

\section{References}

Abelson, R. P. (1981). Psychological status of the script concept. American Psychologist, 36(7), 715-729. doi:10.1037/0003-066X.36.7.715

Ames, C. (1992). Classrooms: Goals, structures, and student motivation. Journal of Educational Psychology, 84(3), 261-271. doi:10.1037/00220663.84.3.261

Andrade, H., \& Valtcheva, A. (2009). Promoting learning and achievement through self-assessment. Theory Into Practice, 48(1), 12-19. doi:10.1080/00405840802577544

Boekaerts, M. (1997). Self-regulated learning: A new concept embraced by researchers, policy makers, educators, teachers, and students. Learning and Instruction, 7(2), 161-186. doi:10.1016/S0959-4752(96)00015-1

Bong, M. (1999, August). Comparison between domain-, task-, and problemspecific academic self-efficacy judgments: Their generality and predictive utility for immediate and delayed academic performances. Paper presented at the annual convention of the America Psychological Association. Boston, MA.

Bong, M. (2004). Academic motivation in self-efficacy, task value, achievement goal orientations, and attributional beliefs. The Journal of Educational Research, 97(6), 287-298. doi:10.3200/JOER.97.6.287-298

Brydges, R., \& Butler, D. (2012). A reflective analysis of medical education research on self-regulation in learning and practice. Medical Education, 46(1), 71-79. doi:10.1111/j.1365-2923.2011.04100.x

Butler, D. L. (1998). Metacognition and learning disabilities. In B. Y. L. Wong (Ed.), Learning about learning disabilities (2nd ed., pp. 277-307). San Diego, CA: Academic Press.

Butler, D. L., \& Cartier, S. C. (2004a, May). Learning in varying activities: An explanatory framework and a new evaluation tool founded on a model of 
self-regulated learning. Paper presented at the annual conference of the Canadian Society for the Study of Education, Winnipeg, Manitoba, Canada.

Butler, D. L., \& Cartier, S. C. (2004b). Promoting effective task interpretation as an important work habit: A key to successful teaching and learning. Teachers College Record, 106(9), 1729-1758.

Butler, D. L., \& Cartier, S. C. (2005, April). Multiple complementary methods for understanding self-regulated learning as situated in context. Paper presented at the annual meeting of the American Educational Research Association, Montréal, Québec, Canada.

Butler, D. L., \& Winne, P. H. (1995). Feedback and self-regulated learning: A theoretical synthesis. Review of Educational Research, 65(3), 245-281. doi:10.3102/00346543065003245

Calkins, E. V., Willoughby, T. L., \& Arnold, L. M. (1982). Predictors of performance of minority students in the first two years of a BA/MD program. Journal of the National Medical Association, 74(7), 625-632. Retrieved from https://www.ncbi.nlm.nih.gov/pmc/articles/PMC2552906/

Cartier, S. C. (1997). Lire pour apprendre: Description des stratégies utilisées par des étudiants en médecine dans un curriculum d'apprentissage par problèmes [Reading to learn: Description of strategies used by medical students within a problem-based curriculum]. Available from ProQuest Dissertations and Theses database. (UMI No. 304406592)

Cartier, S. C., \& Butler, D. L. (2004, May). Elaboration and validation of questionnaires and plan for analysis. Paper presented at the annual conference of the Canadian Society for the Study of Education, Winnipeg, Manitoba, Canada.

Çengel, Y. A., \& Boles, M. A. (2015). Thermodynamics: An engineering approach (8th ed.). New York, NY: McGraw-Hill.

Coutinho, S. A. (2007). The relationship between goals, metacognition, and academic success. Educate The Journal of Doctoral Research in Education, 7(1), 39-47. Retrieved from http://www.educatejournal.org/index.php/educate/article/view/116

Coutinho, S. (2008). Self-efficacy, metacognition, and performance. North American Journal of Psychology, 10(1), 165-172.

Dinsmore, D. L., Alexander, P. A., \& Loughlin, S. M. (2008). Focusing the conceptual lens on metacognition, self-regulation, and self-regulated learning. Educational Psychology Review, 20(4), 391-409. doi:10.1007/s10648-008-9083-6

Eccles, J. (with Adler, T. F., Futterman, R., Goff, S. B., Kaczala, C. M., Meece, J. L., \& Midgley, C.). (1983). Expectancies, values, and academic behaviors. In J. T. Spence (Ed.), Achievement and achievement motives: Psychological and sociological approaches (pp. 75-146). San Francisco, CA: Freeman.

Flavell, J. H. (1979). Metacognition and cognitive monitoring: A new area of 
cognitive-developmental inquiry. American Psychologist, 34(10), 906-911. doi:10.1037/0003-066X.34.10.906

Glaser, R. (1992). Expert knowledge and processes of thinking. In D. F. Halpern (Ed.), Enhancing thinking skills in the sciences and mathematics (pp. 6375). Hillsdale, NJ: Erlbaum.

Hadwin, A. F., Oshige, M., Miller, M., \& Wild, P. M. (2009, July). Examining the agreement between student and instructor task perceptions in a complex engineering design task. Paper presented at the Sixth International Conference on Innovation and Practices in Engineering Design and Engineering Education (CDEN/C2E2), Hamilton, Ontario, Canada.

Herbig, B., \& Glöckner, A. (2009). Experts and decision making: First steps towards a unifying theory of decision making in novices, intermediates and experts. Bonn, Germany: Max Planck Institute for Research on Collective Goods, University of Cologne. doi:10.2139/ssrn.1337449

Hoffman, R. R. (1998). How can expertise be defined? Implications of research from cognitive psychology. In R. Williams, W. Faulkner, \& J. Fleck (Eds.), Exploring expertise: Issues and perspectives (pp. 81-100). London, England: Macmillan. doi:10.1007/978-1-349-13693-3_4

Kearsley, P. D., \& Klein, A. G. (2016, June). Self-corrected homework for incentivizing metacognition (Paper ID No. 16884). Paper presented at the 2016 ASEE Annual Conference \& Exposition, New Orleans, LA. doi: $10.18260 / \mathrm{p} .26155$

Lawanto, O., Butler, D., Cartier, S. C., Santoso, H. B., Goodridge, W., Lawanto, K. N., \& Clark, D. (2013). Pattern of task interpretation and self-regulated learning strategies of high school students and college freshmen during an engineering design project. Journal of STEM Education: Innovations and Research, 14(4), 15-27. Retrieved from https://www.jstem.org/jstem/index.php/JSTEM/article/view/1803

Lawanto, O., Butler, D., Cartier, S., Santoso, H. B., \& Goodridge, W. (2013). Task interpretation, cognitive, and metacognitive strategies of higher and lower performers in an engineering design project: An exploratory study of college freshmen. International Journal of Engineering Education, 29(2), 459-475.

Lawanto, O., Minichiello, A., Uziak, J., \& Febrian, A. (2018). Students' task understanding during engineering problem solving in an introductory thermodynamics course. International Education Studies, 11(7), 43-53. doi:10.5539/ies.v11n7p43

Lesgold, A., Rubinson, H., Feltovich, P., Glaser, R., Klopfer, D., \& Wang, Y. (1988). Expertise in a complex skill: Diagnosing X-ray pictures. In M. T. H. Chi, R. Glaser, \& M. J. Farr (Eds.), The nature of expertise (pp. 311-342). Hillsdale, NJ: Erlbaum.

Marchis, I. (2011). How mathematics teachers develop their pupils' selfregulated learning skills. Acta Didactica Napocensia, 4(2-3), 9-14. 
Retrieved from http://dppd.ubbcluj.ro/adn/article_4_2-3_2.pdf

Markus, H., \& Wurf, E. (1987). The dynamic self-concept: A social psychological perspective. Annual Review of Psychology, 38, 299-337. doi:10.1146/annurev.ps.38.020187.001503

Mattern, R. A. (2005). College students' goal orientations and achievement. International Journal of Teaching and Learning in Higher Education, 17(1), 27-32. Retrieved from http://www.isetl.org/ijtlhe/articleView.cfm?id=11

Miller, R. B., \& Brickman, S. J. (2004). A model of future-oriented motivation and self-regulation. Educational Psychology Review, 16(1), 9-33. doi:10.1023/B:EDPR.0000012343.96370.39

Multon, K. D., Brown, S. D., \& Lent, R. W. (1991). Relation of self-efficacy beliefs to academic outcomes: A meta-analytic investigation. Journal of Counseling Psychology, 38(1), 30-38. doi:10.1037/0022-0167.38.1.30

Otero, J., Campanario, J. M., \& Hopkins, K. D. (1992). The relationship between academic achievement and metacognitive comprehension monitoring ability of Spanish secondary school students. Educational and Psychological Measurement, 52(2), 419-430. doi:10.1177/0013164492052002017

Paris, S. G. (1986). Teaching children to guide their reading and learning. In T. Raphael (Ed.), The context of school-based literacy (pp. 115-130). New York, NY: Random House.

Paris, S. G., \& Winograd, P. (1990). Metacognition in academic learning and instruction. In B. F. Jones \& L. Idol (Ed.), Dimensions of thinking and cognitive instruction (pp. 15-44). Hillsdale, NJ: Erlbaum.

Pekrun, R. (2006). The control-value theory of achievement emotions: Assumptions, corollaries, and implications for educational research and practice. Educational Psychology Review, 18(4), 315-341. doi:10.1007/s10648-006-9029-9

Pintrich, P. R. (2002). The role of metacognitive knowledge in learning, teaching, and assessing. Theory Into Practice, 41(4), 219-225. doi:10.1207/s15430421tip4104_3

Pintrich, P. R., Smith, D. A. F., Garcia, T., \& McKeachie, W. J. (1991). A manual for the use of the Motivated Strategies for Learning Questionnaire (MSLQ) (Technical Report No. 91-8-004). Ann Arbor: University of Michigan.

Samuelsson, J. (2008). The impact of different teaching methods on students' arithmetic and self-regulated learning skills. Educational Psychology in Practice, 24(3), 237-250. doi:10.1080/02667360802256790

Schoenfeld, A. H. (1988). Problem solving in context(s). In R. I. Charles \& E. A. Silver (Eds.), Research agenda for mathematics education: Vol. 3. The teaching and assessing of mathematical problem solving (pp. 82-92). Hillsdale, NJ: Erlbaum; Reston, VA: National Council of Teachers of 
Mathematics.

Schraw, G., Crippen, K. J., \& Hartley, K. (2006). Promoting self-regulation in science education: Metacognition as part of a broader perspective on learning. Research in Science Education, 36(1-2), 111-139. doi:10.1007/s11165-005-3917-8

Schunk, D. H. (1994, April). Student motivation for literacy learning: The role of self-regulatory processes. Paper presented at the Annual Meeting of the American Educational Research Association, New Orleans, LA.

Wigfield, A. (1994). Expectancy-value theory of achievement motivation: A developmental perspective. Educational Psychology Review, 6(1), 49-78. doi:10.1007/BF02209024

Wolters, C. A. (1998). Self-regulated learning and college students' regulation of motivation. Journal of Educational Psychology, 90(2), 224-235. doi:10.1037/0022-0663.90.2.224

Wolters, C. A., Yu, S. L., \& Pintrich, P. R. (1996). The relation between goal orientation and students' motivational beliefs and self-regulated learning. Learning and Individual Differences, 8(3), 211-238. doi:10.1016/S10416080(96)90015-1

Wong, B. Y. L. (1999). Metacognition in writing. In R. Gallimore, L. P. Bernheimer, D. L. MacMillan, D. L. Speece, \& S. Vaughn (Eds.), Developmental perspectives on children with high-incidence disabilities (pp. 183-198). Mahwah, NJ: Erlbaum.

Zimmerman, B. J. (1989). A social cognitive view of self-regulated academic learning. Journal of Educational Psychology, 81(3), 329-339. doi:10.1037/0022-0663.81.3.329

\section{About the Authors}

Oenardi Lawanto (olawanto@usu.edu) is an Associate Professor in the Department of Engineering Education at Utah State University.

Angela Minichiello (angie.minichiello@usu.edu) is an Assistant Professor in the Department of Engineering Education at Utah State University

Jacek Uziak (uziak@mopipi.ub.bw) is a Professor in the Department of Mechanical Engineering at University of Botswana

Andreas Febrian (andreas.febrian@usu.edu) is a PhD Candidate in the Department of Engineering Education at Utah State University 


\section{Modified Task Value Survey}

\section{Appendix}

These questions were taken and modified from the MSLQ:

1. I think I will be able to use what I learn in MAE2300 Thermodynamics in other courses and/or contexts in my life.

2. It is important for me to learn the skills/content taught in MAE2300 Thermodynamics.

3. I am very interested in the skills/content area of MAE2300 Thermodynamics.

4. I think the skills/content gained in MAE2300 Thermodynamics are useful for me to learn.

5. I like the subject matter of MAE2300 Thermodynamics.

6. Understanding the subject matter of MAE2300 Thermodynamics is very important to me.

\section{Problem Example}

An example of a TAQ problem used in this study ${ }^{1}$ :

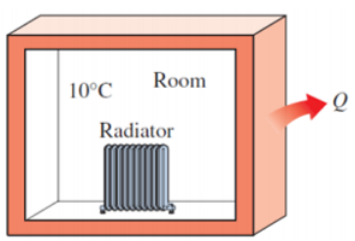

A 40-L electrical radiator containing heating oil is placed in a $50-\mathrm{m} 3$ room. Both the room and the oil in the radiator are initially at $10^{\circ} \mathrm{C}$. The radiator with a rating of $2.4 \mathrm{~kW}$ is now turned on. At the same time, heat is lost from the room at an average rate of $0.35 \mathrm{~kJ} / \mathrm{s}$. After some time, the average temperature is measured to be $20^{\circ} \mathrm{C}$ for the air in the room, and $50^{\circ} \mathrm{C}$ for the oil in the radiator. Taking the density and the specific heat of the oil to be $950 \mathrm{~kg} / \mathrm{m} 3$ and $2.2 \mathrm{~kJ} / \mathrm{kg} \cdot{ }^{\circ} \mathrm{C}$, respectively, determine how long the heater is kept on. Assume the room is well-sealed so that there are no air leaks.

\section{Task Analyzer Questionnaire (TAQ)}

The TAQ are problem-specific questionnaire. These are the TAQ items for the first problem (see the above problem example):

1. (Explicit) What were your goals in solving this problem?

2. (Explicit) Describe the problem-solving procedure you used in solving this problem?

3. (Explicit) In this problem, what substance(s) made up the system you analyzed?

4. (Explicit) In this problem, what forms of energy transferred into or out of the system you analyzed?

\footnotetext{
${ }^{1}$ Copyright (C) McGraw-Hill Education, 2015. Reprinted with permission from Çengel \& Boles (2015). Note: McGraw-Hill makes no representation or warranties as to the accuracy of any information contained in the McGraw-Hill Education Material, including warranties of merchantability or fitness for a particular purpose. In no event shall McGraw-Hill Education have any liability to any party for special, incidental, tort or consequential damages arising out of or in connection with the McGraw-Hill Education Material, even if McGraw-Hill Education has been advised of the possibility of such damages.
} 
5. (Implicit) What resources or information, beyond what is presented in the problem statement, did you use in solving this problem?

6. (Implicit) What kind(s) of thinking (remembering, understanding, applying, evaluating, creating) did you use in solving this problem?

7. (Implicit) List the major concepts and/or principles discussed in class that you used in solving this problem.

8. (Implicit) What was the purpose of solving this particular problem?

An example of possible students' correct responses for the first TAQ item of the given problem was "determine how long the heater was left on in the sealed room based on the change in temperature." An example of a partially correct answer was "find how long the heater had been on." An example of an incorrect answer was "find the Voltage of the source and draw a P-V diagram." 